\title{
Numerical solution of a nozzle flow
}

Report

Author(s):

Fey, Michael; Jeltsch, Rolf; Karmann, P.

Publication date:

1992-07

Permanent link:

https://doi.org/10.3929/ethz-a-004283636

Rights / license:

In Copyright - Non-Commercial Use Permitted

Originally published in:

SAM Research Report 1992-08 


\title{
Numerical solution of a nozzle flow ${ }^{1}$
}

\author{
M. Fey, R. Jeltsch, P. Karmann
}

Research Report No. 92-08

July 1992

Seminar für Angewandte Mathematik

Eidgenössische Technische Hochschule

CH-8092 Zürich

Switzerland

\footnotetext{
${ }^{1}$ This research has been supported by the research and development program in the Hermes preparatory phase under contract RDANE 19/87 Step 3.
} 


\title{
Numerical solution of a nozzle flow
}

\author{
M. Fey, R. Jeltsch, P. Karmann \\ Seminar für Angewandte Mathematik \\ Eidgenössische Technische Hochschule \\ CH-8092 Zürich \\ Switzerland
}

Research Report No. 92-08 July 1992

\begin{abstract}
The problem of a high enthalpy nozzle flow is considered. Rotational symmetry is assumed. The governing inhomogeneous Euler equations are given, and the special treatment of the high temperature gas, the vibrational and chemical equilibrium is described. Some numerical boundary conditions are given and the problem of rotational symmetry is mentioned. At the end some numerical results are shown.
\end{abstract}

Key words: high enthalpy flow, rotational symmetry, operator splitting, non-equilibrium

Subject Classification: 35L65, 65M99, 76K05, 76N15 


\section{Introduction}

In high temperature flow such as the reentry of a space vehicle or a high enthalpy flow in a nozzle the equations describing the fluid motion become inhomogeneous. For temperatures of $5000 K$ and high total pressure as it arises in shock tubes, chemical reactions take place and they are not in equilibrium with the thermodynamical states. Even some thermodynamical properties such as vibrational energy are assumed to be in non-equilibrium.

In the following discussion the flow in a nozzle with high total enthalpy and pressure is numerically simulated. We assume thermodynamical equilibrium only for the translational and rotational modes of the particles. The chemical reactions as well as the vibrational energies of the molecules are taken in non-equilibrium. We will briefly describe the equations, the numerical method and the boundary conditions. At the end some numerical results for the test case VIII.2 are shown.

\section{The governing equations}

High temperature inviscid flows are described by the conservation equations for the partial densities of the different chemical species, the momentum, the total energy and the vibrational energies which can be written in two dimensions in the form

$$
\frac{\partial U}{\partial t}+\frac{\partial F(U)}{\partial x}+\frac{\partial G(U)}{\partial y}=S(U)
$$

The vector $U$ has the form $U=\left(\rho_{1}, \ldots, \rho_{N}, m, n, E, E_{V_{1}}, \ldots, E_{V_{K}}\right)^{T}$ where the $E_{V_{j}}$ represent the different vibrational energies. The fluxes and the source term have the form

$$
F(U)=\left(\begin{array}{c}
\rho_{1} \frac{m}{\rho} \\
\vdots \\
\rho_{N} \frac{m}{\rho} \\
\frac{m^{2}}{\rho}+p \\
\frac{m n}{\rho} \\
(E+p) \frac{m}{\rho} \\
\frac{m}{\rho} E_{V_{1}} \\
\vdots \\
\frac{m}{\rho} E_{V_{K}}
\end{array}\right) ; \quad G(U)=\left(\begin{array}{c}
\rho_{1} \frac{n}{\rho} \\
\vdots \\
\rho_{N} \frac{n}{\rho} \\
\frac{n m}{\rho} \\
\frac{n^{2}}{\rho}+p \\
(E+p) \frac{n}{\rho} \\
\frac{n}{\rho} E_{V_{1}} \\
\vdots \\
\frac{n}{\rho} E_{V_{K}}
\end{array}\right) ; \quad S(U)=\left(\begin{array}{c}
s_{1} \\
\vdots \\
s_{N} \\
0 \\
0 \\
0 \\
\psi_{1} \\
\vdots \\
\psi_{K}
\end{array}\right) .
$$

The quantities $\rho_{i}, i=1, \ldots, N$ denote the partial densities of the $N$ different chemical species of the mixture, $m$ and $n$ are the momenta in $x$ - and $y$-direction, $E$ is the total energy per unit volume, $\rho=\sum_{i=1}^{N} \rho_{i}$ is the total density of the mixture, $p$ is the pressure, $u=m / \rho$ and $v=n / \rho$ are the components of the fluid velocity. The terms $s_{i}$ characterize the production of the $i$ th species due to chemical reactions and the $\psi_{k}$ describe the energy exchange between the vibrational states and the modes in equilibrium. In order to get a closed set of equations the pressure $p$ and the source term have to be related to the $N+3+K$ components of $U$.

The evaluation of the flow properties is very easy because we only have a mixture of ideal gases although the physical model is complex. The equilibrium temperature can be obtained from the equation of the total energy by an explicit formula because 
the heat capacities are not a function of temperature. We have

$$
T=\frac{E-\left(E_{k i n}+E_{h}+E_{V}\right)}{\rho c_{v}}
$$

where $E_{k i n}$ is the kinetic energy, $E_{h}=\sum \rho_{i} h_{i}^{0}$ is the heat of formation and $E_{V}=$ $\sum E_{V_{j}}$ is the total vibrational energy. The term $c_{v}=\sum Y_{i} c_{v_{i}}$ is the heat capacity of the gas at constant volume. The pressure is given by the equation of state $p=\rho R T \sum Y_{i} / W_{i}$ with the molar mass $W_{i}$.

\section{Description of the source term}

For the chemical reactions we use the five species model of air consisting of $N_{2}, O_{2}$, N, O, NO with 17 reactions introduced by Park. A complete table of the reactions together with the corresponding empirical factors for the reaction rates and the equilibrium constants is given in [5]. The source term for the chemical reactions appearing in the equations is determined by the law of mass action as described in [2]. The source term for the vibrational energies depends strongly on the physical model and the data used. The $\psi_{j}$ are given by

$$
\psi_{j}=\frac{e_{V_{j}}^{E}-e_{V_{j}}}{\tau_{j}}
$$

where the relaxation time $\tau_{j}$ is based on a Landau-Teller theory and the vibrational energies $e_{V_{j}}$ (in mole $/ \mathrm{m}^{3}$ ) are given by

$$
e_{V_{j}}=\frac{R \Theta_{j}}{\exp \left(\frac{\Theta_{j}}{T}\right)-1}
$$

from the simple physical model of a harmonic oscillator. The $\Theta_{j}$ are the vibrational

temperatures and the $e_{V_{j}}^{E}$ are the equilibrium vibrational energies (e.g. $e_{V_{j}}$ evaluated at the equilibrium temperature). The vibrational energies per unit volume are given by $E_{V_{j}}=e_{V_{j}} / W_{j}$.

\section{Operator splitting}

The basic idea for solving the equation (1) is to split it into an system of ODEs for the source term and the homogeneous Euler equations. Note that during the first step, the integration of the system of ODEs

$$
\frac{d U}{d t}=S(U)
$$

the $x$ - and $y$-momenta, the total energy and the total density are constant. In the second step while solving the homogeneous Euler equations

$$
\frac{\partial U}{\partial t}+\frac{\partial F(U)}{\partial x}+\frac{\partial G(U)}{\partial y}=0
$$

the mass fractions $Y_{i}=\rho_{i} / \rho$ and the vibrational energies $E_{V_{j}}$ stay constant. For the nozzle flow the system of ODEs is stiffer than for the double ellipse because of 
the different flow conditions (see [4]). Here the eigenvalues of the Jacobian of the chemical source terms are in the range of $-10^{9}$ in contrast to $-10^{7}$ for the reentry. For the vibrational states stiffness becomes more pronounced. Here the relaxation times are in the range of $10^{-13} s$ and so the eigenvalues are less than $-10^{13}$. Therefore we use the implicit Euler scheme for the source term. It is not obvious whether this method is feasible. Further investigations are needed to check the coupling between the chemical reactions, the vibrational relaxation and the flowfield. The solution of the homogenious Euler equations is obtained using a low diffusion Van Leer flux vector splitting [3]. The vibrational energies are treated in the same way as the partial densities.

\section{Numerical results}

The geometry and the free stream conditions are taken from the specifications of the Workshop on Hypersonic Reentry Problems [1], Part II. The testcase VIII.2 is considered here. Up to now we only use one vibrational temperature and noncatalytic boundary condition. For the calculation we used a grid with nearly the same space discretization in both directions so that the region near the inlet is better resolved. Rotational symmetry is taken into account. The results shown in the plots were obtained on a mesh with 666 points in $\mathrm{x}$ - and 30 points in y-direction. At the inlet we used a Mach number of 1.0 and data equivalent to the total pressure and temperature prescribed in testcase VIII.2. As inflow boundary condition the free stream values are used at the point $x=0$. At the outflow boundary we only use information from inner points because of supersonic outflow. To obtain the boundary condition on the wall we connect the state in front of the wall to a state with normal velocity zero at the wall by an expansion wave. The walls are noncatalytic in contrast to the specifications of testcase VIII.2. The following plots show the numerical results. The solution is considered to be converged if the relative variation of the conserved quantities is less than $10^{-8}$. There is a strong influence of the boundary conditions at the symmetry axis. This influence only appears in the steady state limit. During the time accurate computation the initial shock wave propagates with the correct shape. The errors near the symmetry line are not caused by the chemical reactions or the vibrational non-equilibrium.

\section{Acknowledgement}

We thank the Rechenzentrum at ETH Zürich for the opportunity to use the CRAYYMP.

\section{References}

[1] Book of Abstracts of the Workshop on Hyperbolic Flows for Reenry Problems, Part II, April 15-19, 1991, volume 4, 1991.

[2] Michael Fey, Helmut Jarausch, Rolf Jeltsch, and Peter Karmann. On the Interaction of Euler and ODE Solver when Computing Reactive Gas Flow. In J. E. Flaherty, P. J. Paslow, M. S. Shephard, and J. D. Vasilakis, editors, Proceedings of the Workshop on Adaptive Computational Methods for Partial Differential Equations. SIAM, 1988. 
[3] Michael Fey and Rolf Jeltsch. Influence of numerical diffusion in high temperature flow. In I. L. Rhyming, editor, Proceedings of the 9th GAMM Conference on Numerical Methods in Fluid Dynamics, Notes on Numerical Fluid Mechanics. Vieweg Verlag, 1992.

[4] Michael Fey, Rolf Jeltsch, and Peter Karmann. Special aspects of reacting inviscid blunt body flow. In J.-A. Désidéri, R. Glowinski, and J. Périaux, editors, Hypersonic Flows for Reentry Problems, Proceedings of the Workshop held in Antibes, France, April, 1991, volume 3. Springer Verlag, to appear.

[5] Chul Park. On convergence of computation of chemically reacting flows. Technical Report 085-0247, AIAA, 1985. 


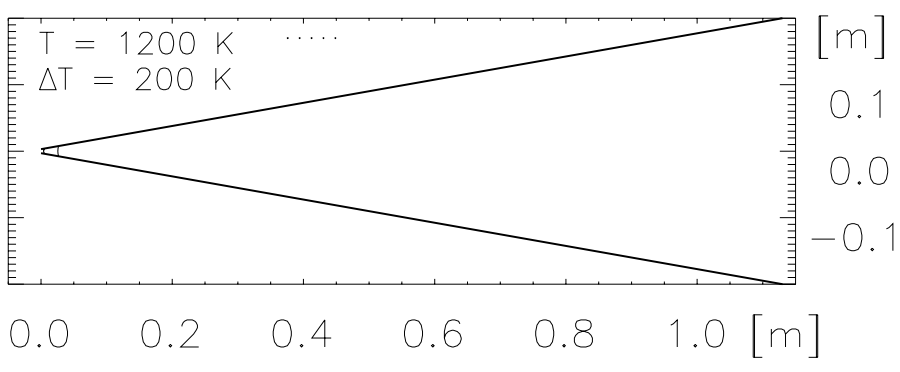

CASE VIII.2: VIBR. TEMPERATURE CONTOURS

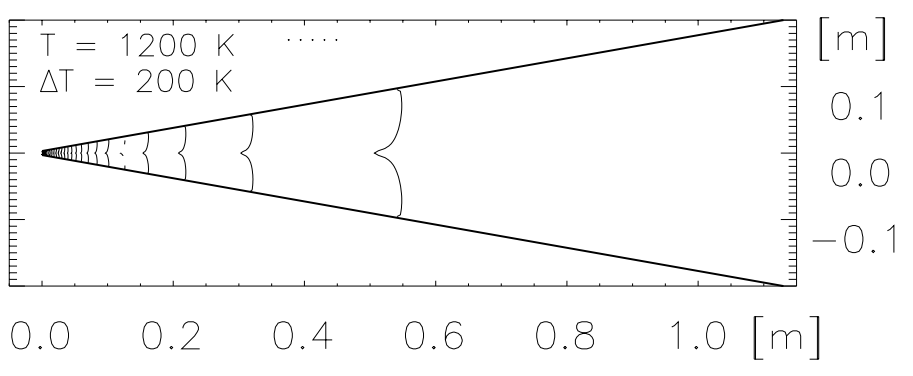

CASE VIII.2: TEMPERATURE CONTOURS

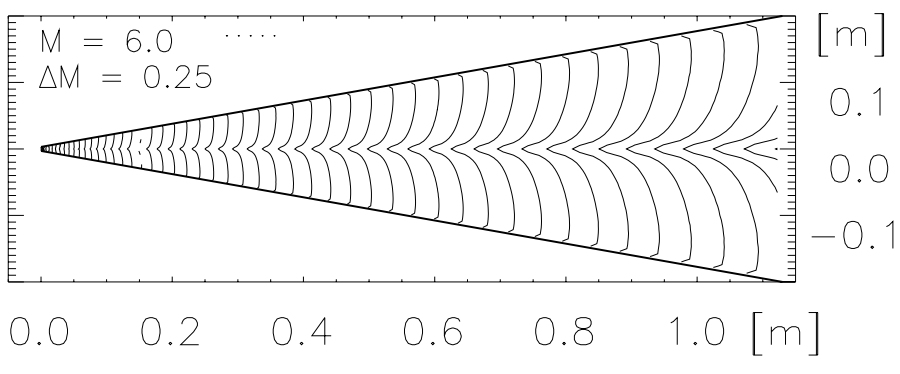

CASE VIII.2: MACH NUMBER CONTOURS 


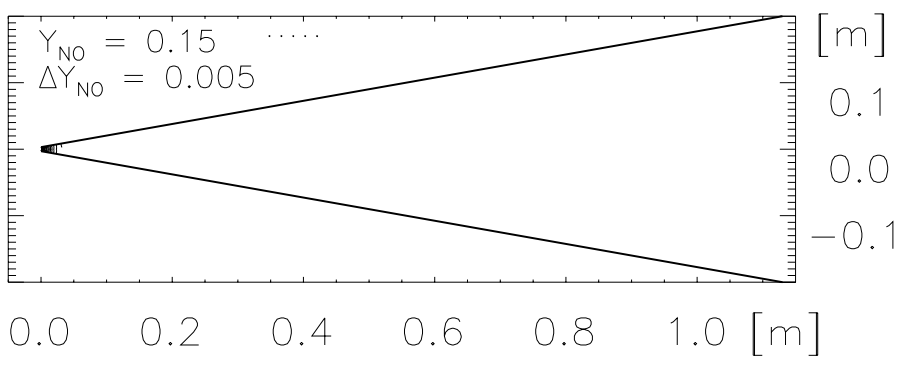

CASE VIII.2: MASS FRACTION CONTOURS OF Y NO $_{\text {NON }}$

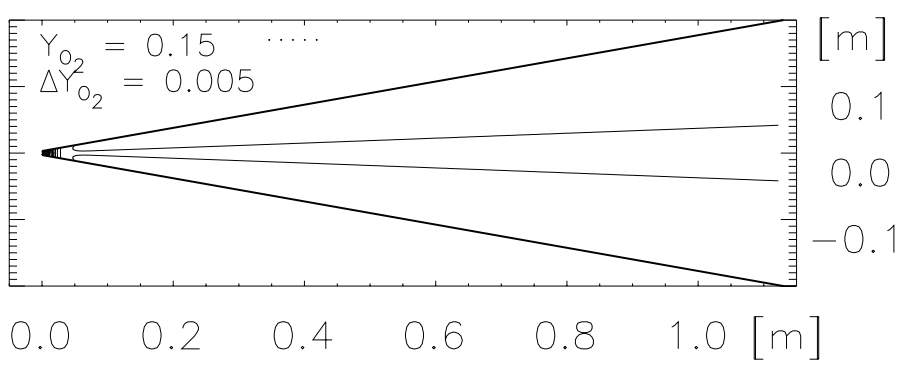

CASE VIII.2: MASS FRACTION CONTOURS OF $\mathrm{Y}_{\mathrm{O}_{2}}$

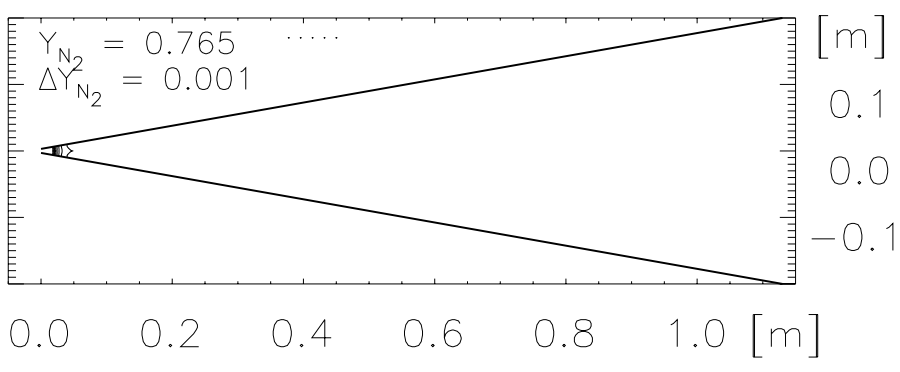

CASE VIII.2: MASS FRACTION CONTOURS OF $Y_{\mathrm{N}_{2}}$ 


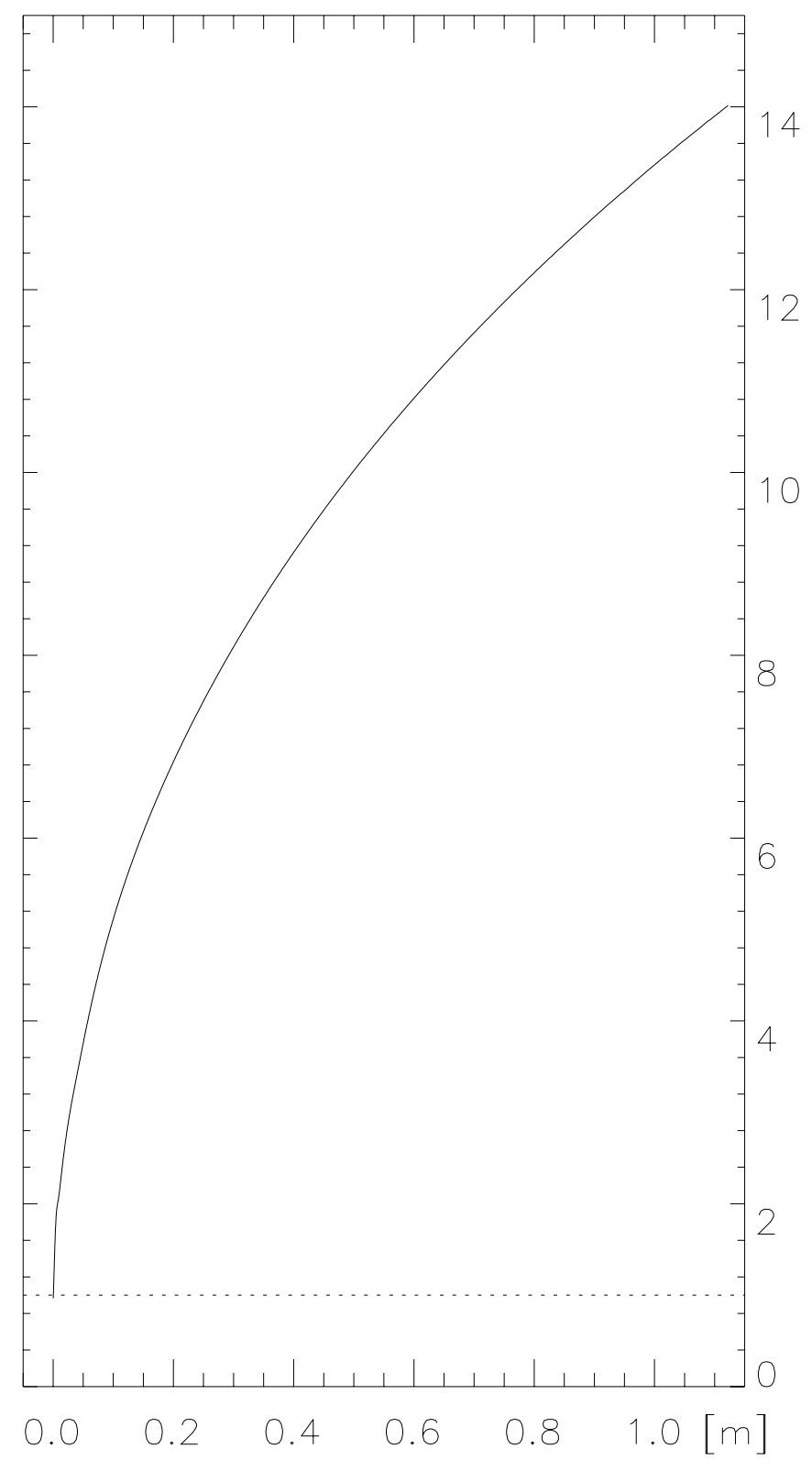

CASE VIII.2: MACH NUMBER IN SYMMETRY AXIS 


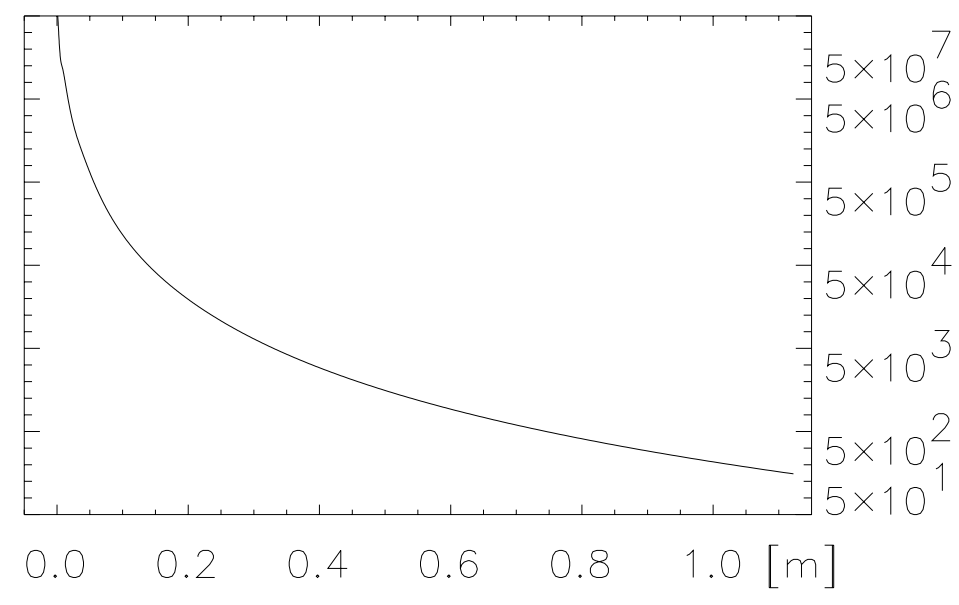

CASE VIII.2: PRESSURE AT SYMMETRY AXIS

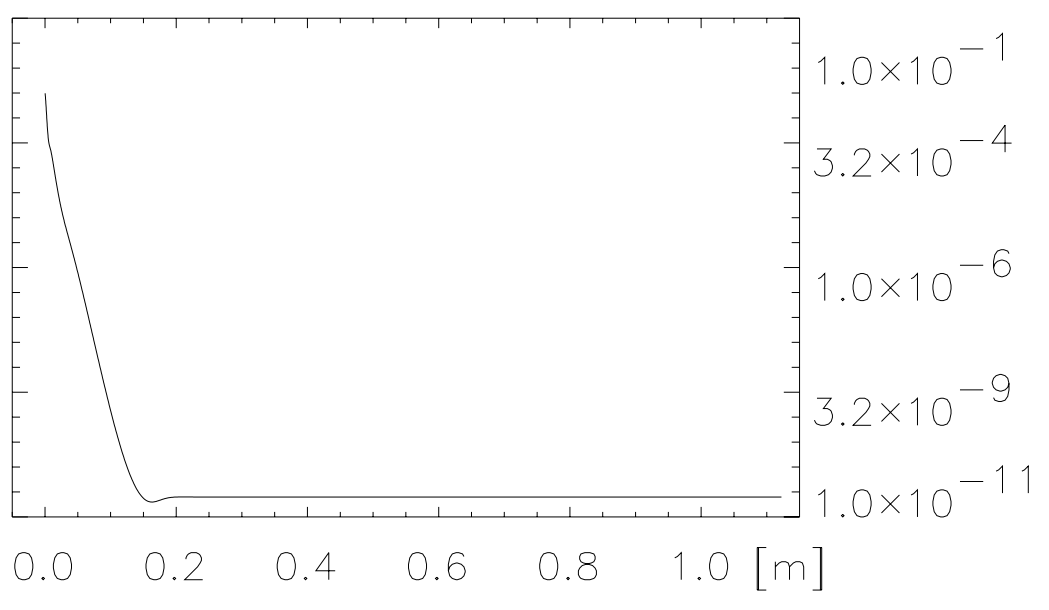

CASE VIII.2: Y Y AT SYMMETRY AXIS 


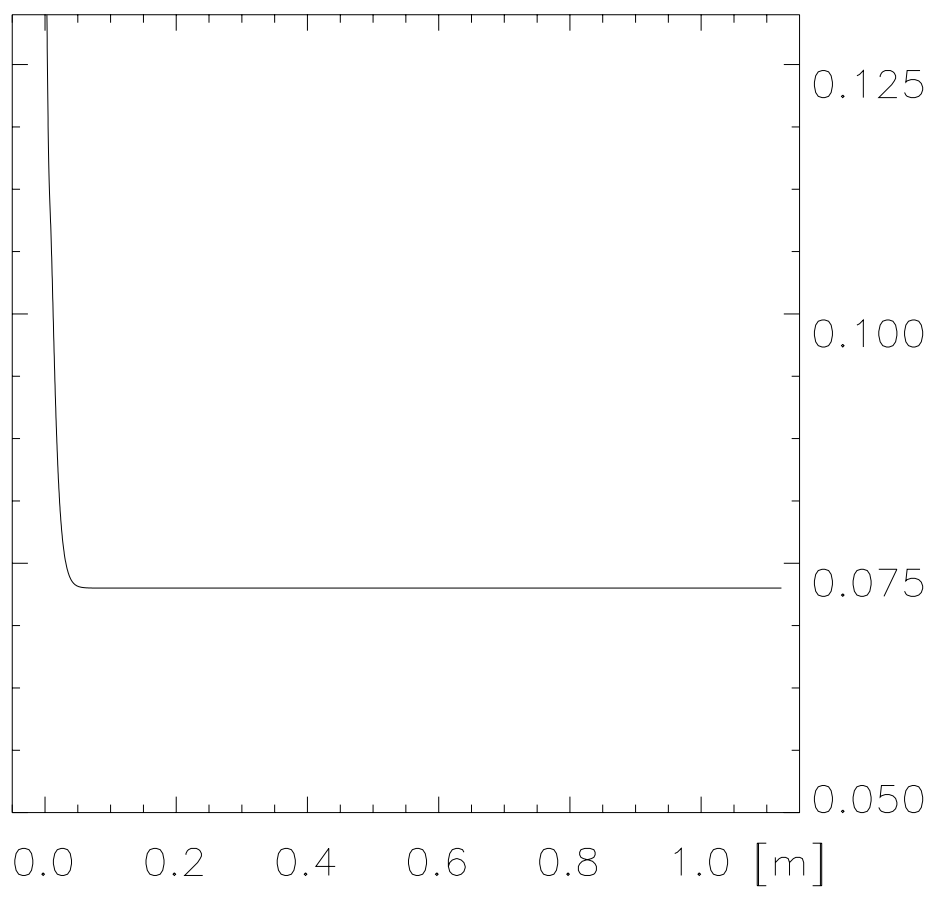

CASE VIII.2: Y ${ }_{\text {NO }}$ AT SYMMETRY AXIS

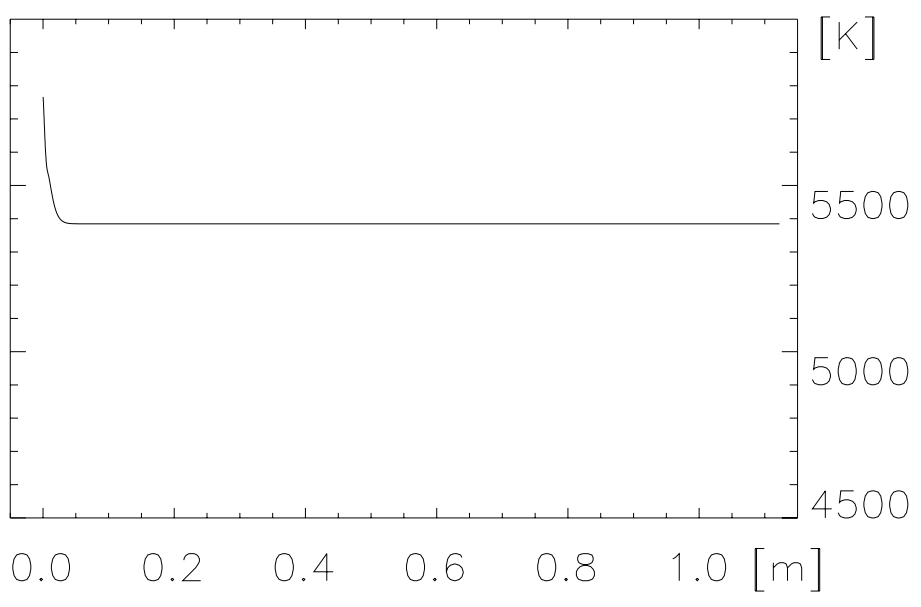

CASE VIII.2: VIBR. TEMPERATURE AT SYMMETRY AXIS 


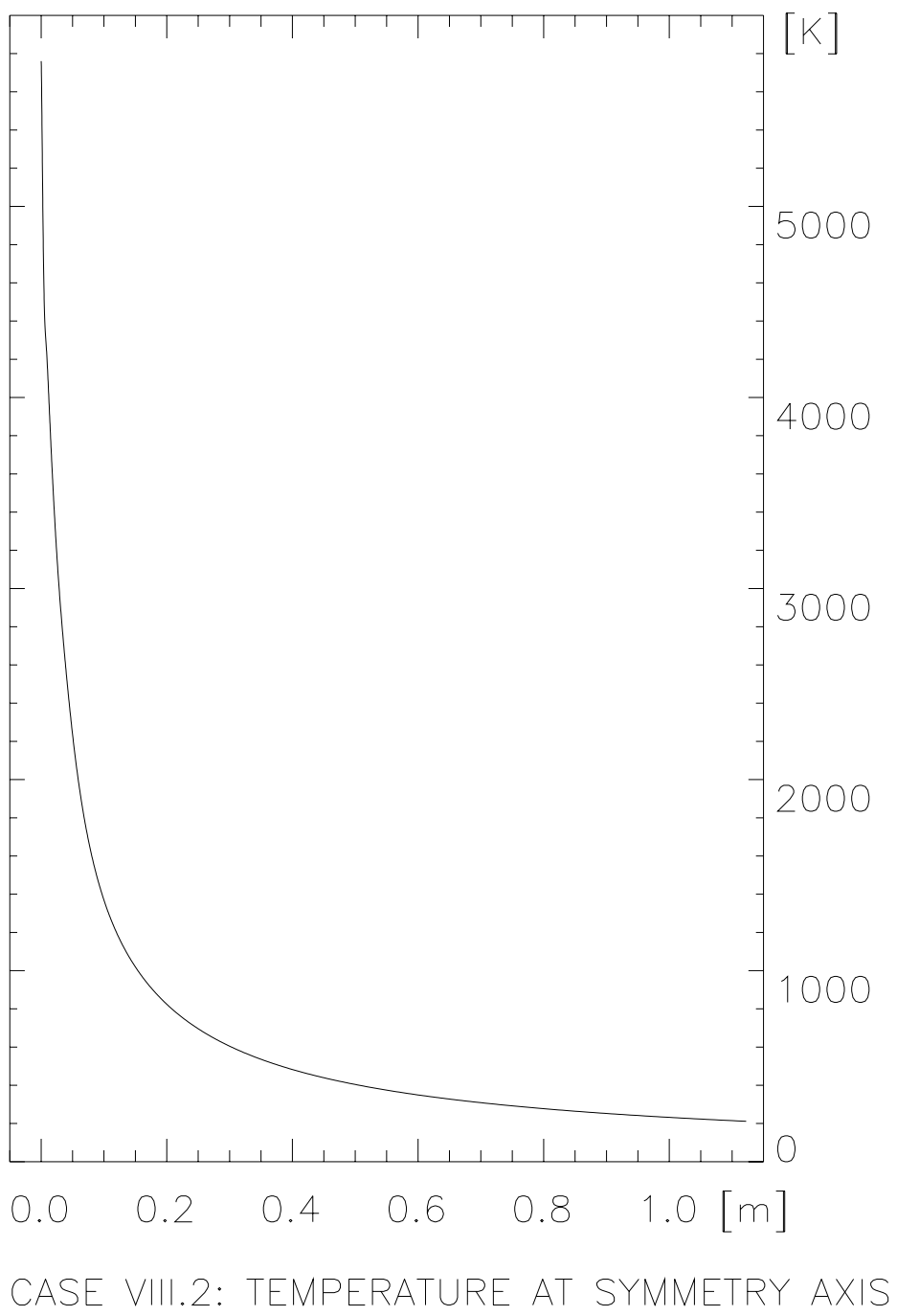




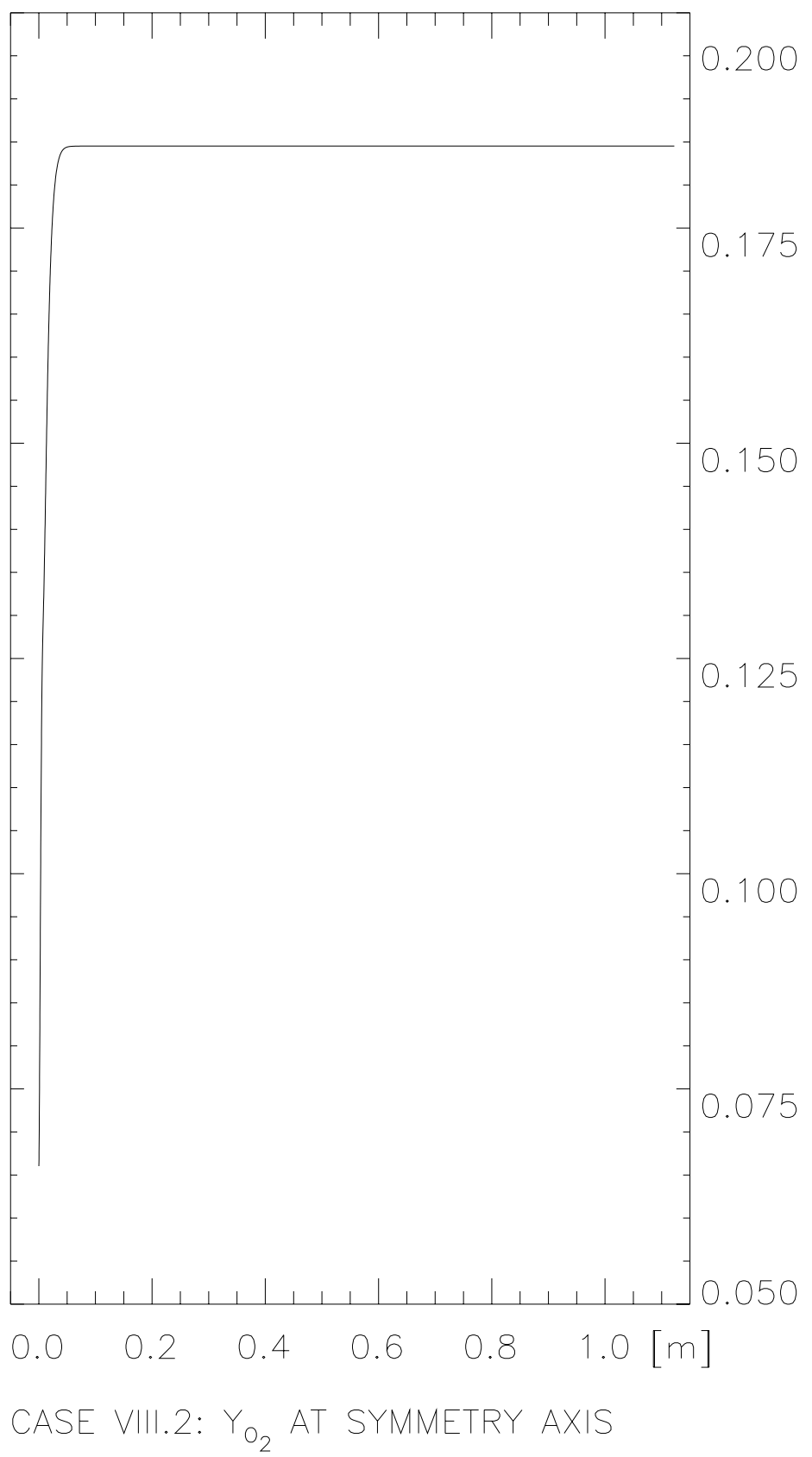




\section{Research Reports}

\begin{tabular}{|c|c|c|}
\hline No. & Authors & Title \\
\hline $92-08$ & $\begin{array}{l}\text { M. Fey, R. Jeltsch, } \\
\text { P. Karmann }\end{array}$ & Numerical solution of a nozzle flow \\
\hline $92-07$ & $\begin{array}{l}\text { M. Fey, R. Jeltsch, } \\
\text { P. Karmann }\end{array}$ & $\begin{array}{l}\text { Special aspects of reacting inviscid blunt } \\
\text { body flow }\end{array}$ \\
\hline $92-06$ & $\begin{array}{l}\text { M. Fey, R. Jeltsch, } \\
\text { S. Müller }\end{array}$ & $\begin{array}{l}\text { The influence of a source term, an example: } \\
\text { chemically reacting hypersonic flow }\end{array}$ \\
\hline $92-05$ & N. Botta, J. Sesterhenn & $\begin{array}{l}\text { Deficiencies in the numerical computation of } \\
\text { nozzle flow }\end{array}$ \\
\hline $92-04$ & Ch. Lubich & $\begin{array}{l}\text { Integration of stiff mechanical systems by } \\
\text { Runge-Kutta methods }\end{array}$ \\
\hline $92-03$ & M. Fey, R. Jeltsch, S. Müller & Stagnation point analysis \\
\hline $92-02$ & $\begin{array}{l}\text { C. W. Schulz-Rinne, } \\
\text { J. P. Collins, H. M. Glaz }\end{array}$ & $\begin{array}{l}\text { Numerical Solution of the Riemann Problem } \\
\text { for Two-Dimensional Gas Dynamics }\end{array}$ \\
\hline $92-01$ & $\begin{array}{l}\text { R. J. LeVeque, } \\
\text { K. M. Shyue }\end{array}$ & $\begin{array}{l}\text { Shock Tracking Based on High Resolution } \\
\text { Wave Propagation Methods }\end{array}$ \\
\hline $91-10$ & M. Fey, R. Jeltsch & $\begin{array}{l}\text { Influence of numerical diffusion in high tem- } \\
\text { perature flow }\end{array}$ \\
\hline $91-09$ & R. J. LeVeque, R. Walder & $\begin{array}{l}\text { Grid Alignment Effects and Rotated Meth- } \\
\text { ods for Computing Complex Flows in Astro- } \\
\text { physics }\end{array}$ \\
\hline $91-08$ & Ch. Lubich, R. Schneider & $\begin{array}{l}\text { Time discretization of parabolic boundary in- } \\
\text { tegral equations }\end{array}$ \\
\hline $91-07$ & M. Pirovino & $\begin{array}{l}\text { On the Definition of Nonlinear Stability for } \\
\text { Numerical Methods }\end{array}$ \\
\hline $91-06$ & $\begin{array}{l}\text { Ch. Lubich, } \\
\text { A. Ostermann }\end{array}$ & $\begin{array}{l}\text { Runge-Kutta Methods for Parabolic Equa- } \\
\text { tions and Convolution Quadrature }\end{array}$ \\
\hline $91-05$ & C. W. Schulz-Rinne & $\begin{array}{l}\text { Classification of the Riemann Problem for } \\
\text { Two-Dimensional Gas Dynamics }\end{array}$ \\
\hline $91-04$ & R. Jeltsch, J. H. Smit & $\begin{array}{l}\text { Accuracy Barriers of Three Time Level Dif- } \\
\text { ference Schemes for Hyperbolic Equations }\end{array}$ \\
\hline $91-03$ & I. Vecchi & Concentration-cancellation and Hardy spaces \\
\hline $91-02$ & R. Jeltsch, B. Pohl & $\begin{array}{l}\text { Waveform Relaxation with Overlapping } \\
\text { Splittings }\end{array}$ \\
\hline
\end{tabular}

